\title{
INTERVERTEBRAL DISC REPAIR WITH ACTIVATED NUCLEUS PULPOSUS CELL TRANSPLANTATION: A THREE-YEAR, PROSPECTIVE CLINICAL STUDY OF ITS SAFETY
}

\author{
J. Mochida ${ }^{1,2, *}$, D. Sakai ${ }^{1,2}$, Y. Nakamura ${ }^{2}$, T. Watanabe ${ }^{1,2}$, Y. Yamamoto ${ }^{1}$ and S. Kato ${ }^{2}$ \\ ${ }^{1}$ Department of Orthopaedic Surgery, Surgical Science, Tokai University School of Medicine, Isehara, \\ Kanagawa, Japan \\ ${ }^{2}$ The Research Centre for Regenerative Medicine, Tokai University School of Medicine, \\ Isehara, Kanagawa, Japan
}

\begin{abstract}
Degeneration of the lumbar intervertebral discs is irreversible, with no treatment currently available. Building upon experimental studies that demonstrated the importance of the nucleus pulposus (NP) in preserving disc structure, we demonstrated that reinsertion of NP cells slowed further disc degeneration and that direct cell-tocell contact co-culture with mesenchymal stromal cells (MSCs) significantly upregulated the viability of NP cells in basic and pre-clinical studies in vitro and in vivo using animal models and human cells. Here, we report a 3-year result of a prospective clinical study, aimed to assess the safety and efficacy of activated NP cell transplantation in the degenerate lumbar intervertebral disc. Candidates were 9 patients aged 20-29 years who had Pfirrmann's grade III disc degeneration at the level adjacent to the level scheduled for posterior lumbar intervertebral fusion. Viable NP cells from the fused disc were co-cultured in direct contact with autologous bone marrow-derived MSCs. One million activated NP cells were transplanted into the degenerated disc adjacent to the fused level at $7 \mathrm{~d}$ after the first fusion surgery. No adverse effects were observed during the 3-year follow-up period. Magnetic resonance imaging did not show any detrimental effects to the transplanted discs and revealed a mild improvement in 1 case. No cases reported any low back pain. Our clinical study confirmed the safety of activated NP cell transplantation, and the findings suggest the minimal efficacy of this treatment to slow the further degeneration of human intervertebral discs.
\end{abstract}

Keywords: Intervertebral disc repair, cell transplantation, nucleus pulposus cells, mesenchymal stromal cells, cellto-cell contact co-culture, safety of activated nucleus pulposus cells.

\author{
*Address for correspondence: \\ Prof. Joji Mochida \\ Department of Orthopaedic Surgery, Surgical Science \\ Tokai University School of Medicine \\ 143 Shimokasuya \\ Isehara Kanagawa, 259-1193, Japan
}

Telephone Number: +81-463-93-1121

FAX Number: +81-463-96-4404

E-mail: jomo@is.icc.u-tokai.ac.jp

\section{Introduction}

Low back pain is one of the most common reasons for visits to physicians (Deyo and Weinstein, 2001). Intervertebral disc (IVD) degeneration is a major cause of low back complaints and is a leading cause of health-care costs and patient morbidity. However, the causes of IVD degeneration are still largely unknown. The processes associated with the disorder are thought to involve sequential events that lead to a loss of cells and the associated matrix, which is composed of collagen and proteoglycans. This leads to the associated loss of functions of the spinal column with disc degeneration, such as impairment of spinal motion, and the stabilisation and protection of the neural elements, possibly ending in symptomatic disc disorders (Anderson and Tannoury, 2005). Furthermore, various surgical procedures can accelerate disc degeneration. Procedures such as microscopic discectomy or spinal fusion are clinically effective, but do not preserve the function of the IVD and increase the mechanical loads to the discs. Therefore, new strategies that restore the biological function of the IVD and preserve the motion segment are needed.

Recent advances in molecular biology have resulted in experimental studies that have explored biological strategies to address disc degeneration. These strategies include the induction of growth factors and cytokines, gene therapy, tissue engineering (Alini et al., 2002; An et al., 2003; Nishida et al., 1998), and cell supplementation by transplantation therapy. Cell transplantation is a new therapy that is based on the supplementation of matrixproducing cells in an attempt to correct the decrease of matrix components, primarily proteoglycan and collagen, a major factor in disc degeneration. Various types of cell transplantation therapy have been initiated (Sakai et al., 2003; Meisel et al., 2007; Hohaus et al., 2008).

On the other hand, results from clinical studies on preserving the disc structure in microscopic discectomy and percutaneous nucleotomy for lumbar disc herniation have shown the importance of preserving the nucleus pulposus (NP) elements to prevent an acceleration of disc degeneration after such surgical approaches (Mochida et al., 1996; Mochida et al., 2001). These studies also opened a new era of research where supplementation of the NP cells may potentially decelerate the speed of progression of disc degeneration.

We have primarily focused these research efforts on disc regeneration, especially on repair of the NP using cell therapy. In 1998, we first reported that reinsertion of autologous normal NP tissue could decelerate further 
disc degeneration in a rat model (Nishimura and Mochida, 1998). We then found that the biological viability of NP cells could be activated using a co-culture system with annulus fibrosus cells (Okuma et al., 2000). However, the NP tissue yielded low cellularity and low proliferative activity in the earlier phases of primary culture, and further upregulation of the metabolic and biological viability was necessary to achieve effective enhancement of the NP cells. To resolve this problem, the development of a new activation method to co-culture NP cells with various feeding cells was required. Yamamoto et al. (2004) demonstrated significant activation of NP cells with co-culture having direct cell-to-cell contact with mesenchymal stromal cells (MSCs). This innovative coculture method with direct cell-to-cell contact showed a 20-fold increase of DNA synthesis data and a 15-fold increase of glycosaminoglycan (GAG) synthesis data compared with those from a monoculture. Furthermore, in an in vivo animal study using chondrodystrophic beagles, intervertebral discs with transplantation of activated NP cells showed sufficient water content and maintenance of Pfirrmann's grade II condition on T2-weighted magnetic resonance imaging (MRI) at the 24-week follow-up (Iwashina et al., 2008). We confirmed that the reinsertion of activated NP cells attenuated further disc degeneration.

Based on the promising data acquired with animal models, we initiated an in vitro clinical study to determine whether autologous MSC-mediated NP cell activation was safe when applied to human NP cells (Watanabe et al., 2010). Human NP tissue was obtained from surgical specimens and MSCs were obtained from the bone marrow of 10 subjects, aged 19-38 years. Six-well culture plates and inserts were used for co-culture; $1.0 \times 10^{4} \mathrm{NP}$ cells were seeded onto each insert and incubated alone, in standard co-culture with $1.0 \times 10^{4} \mathrm{MSCs}$, or co-cultured with direct cell-to-cell contact. The results demonstrated a significant positive effect on the proliferation of NP cells, DNA synthesis, and proteoglycan synthesis, of human NP cells in co-culture with direct cell-to-cell contact. Chromosome abnormalities in the activated NP cells and tumourigenesis of the cells were evaluated in an additional 10 patients by microscopic examination of cell morphology and histological assessment of activated cells transplanted into nude mice. The cells showed no apparent chromosomal abnormalities or tumourigenic abilities. This study confirmed that a co-culture system with direct cell-to-cell contact demonstrated a significantly positive effect in human material, as observed in animal models. These results provided useful information for designing and conducting trials leading to the clinical use of activated NP cell transplantation.

Confirming efficacy and safety of activated NP cells in the above listed basic and pre-clinical studies, we moved forward to designing a clinical study. The primary purpose of this study was to assess the safety of autologous activated NP cell transplantation in patients with degenerated intervertebral disc, with information on minimal efficacy. At the time of study design in 2008, all clinical studies using human cells performed in Japan had to be reported and approved by the Ministry Health, Labour and Welfare (MHLW) to meet the Guidelines on Ensuring the Quality and Safety of Products Derived from Processed Human Stem Cells posted by MHLW in 2008. After refinements of the protocol, standard operation procedure to meet the standards of good tissue practice (GTP) taking place in the Cell Processing Centre (CPC) at Tokai University Hospital, the current study was approved by MHLW in January 2008. Here we report the 3-year result of a prospective clinical study.

\section{Materials and Methods}

The current study was approved by the MHLW of Japan to meet the Guidelines on Ensuring the Quality and Safety of Products Derived from Processed Human Stem Cells (No. 0124001). The study was conducted in accordance with protocols approved by the Experimentation Ethics Committee and the Institutional Review Board for Clinical Studies of the Tokai University School of Medicine including informed consent forms for patients (No. 06I-49).

\section{Criteria for enrolment in the clinical study}

The inclusion criteria for enrolment in the clinical study were: patients aged 20 to 29 years who had moderate IVD degeneration, such as Pfirrmann's grade III (Pfirrmann et al., 2001) or Mochida's moderate dehydration on MRI (Mochida et al., 1996), instability less than $15^{\circ}$ angle with lateral dynamic radiograph, posterior spreading less than $5^{\circ}$ angle when standing on lateral radiograph, and no forward-backward slipping at the level adjacent to the level for which they were scheduled to have posterior lumbar intervertebral fusion to treat significant disc degeneration, such as lumbar disc herniation, lumbar spondylolytic lesion, or lumbar discopathy. Nine patients were enrolled (8 males and 1 female), and all matched the patient selection criteria. The disc degeneration pathologies in this clinical series included 2 patients with lumbar disc herniation and 7 patients with lumbar discopathy (Table 1).

Table 1. Enrolled patients.

\begin{tabular}{|c|c|c|c|c|c|c|c|c|c|}
\hline Case & 1 & 2 & 3 & 4 & 5 & 6 & 7 & 8 & 9 \\
\hline Sex & $\mathrm{M}$ & $\mathrm{M}$ & $\mathrm{M}$ & $\mathrm{M}$ & $\mathrm{M}$ & $\mathrm{M}$ & $\mathrm{M}$ & $\mathrm{M}$ & $\mathrm{F}$ \\
\hline Age(Y-M) & $21-10$ & $28-7$ & $28-2$ & $27-11$ & $29-11$ & $28-5$ & $21-3$ & $28-9$ & $21-0$ \\
\hline Intervertebral fusion level & $\mathrm{L} 5 / \mathrm{S} 1$ & L5/S1 & $\mathrm{L} 4 / 5$ & $\mathrm{~L} 5 / \mathrm{S} 1$ & L5/S1 & $\mathrm{L} 4 / 5$ & $\mathrm{~L} 4 / 5$ & $\mathrm{~L} 4 / 5$ & $\mathrm{~L} 4 / 5$ \\
\hline Transplantation level of activated NP cells & $\mathrm{L} 4 / 5$ & L4/5 & L5/S1 & $\mathrm{L} 4 / 5$ & $\mathrm{~L} 4 / 5$ & $\mathrm{~L} 3 / 4$ & $\mathrm{~L} 3 / 4$ & L5/S1 & $\mathrm{L} 3 / 4$ \\
\hline Disc degeneration pathology of the transplantation level & LDH & $\mathrm{D}$ & $\mathrm{D}$ & $\mathrm{D}$ & $\mathrm{D}$ & $\mathrm{D}$ & $\mathrm{D}$ & LDH & $\mathrm{D}$ \\
\hline
\end{tabular}

LDH: lumbar disc herniation; D: lumbar discopathy. 


\section{Cell isolation}

At the first fusion surgery, peripheral blood $(100 \mathrm{~mL})$ was collected without anti-coagulant during the surgery. The syringe including the blood was left in an enclosed sterilised stainless steel box and transported to the CPC at our institution. In the safety cabinet of the $\mathrm{CPC}$, the peripheral blood was allowed to stand for $1 \mathrm{~h}$ at room temperature, to achieve a complete coagulation reaction. After coagulation, the blood sample underwent centrifugation at $1100 \times g$ for $10 \mathrm{~min}$, and the supernatant of the serum was separated. A portion of the serum was retained for sterility testing. The culture medium (DMEM/F12 culture medium containing $10 \%$ autologous serum; DMEM/F12/10 \% AS) was made with $45 \mathrm{~mL}$ antibiotic-free Dulbecco's modified Eagle's medium (DMEM)/Ham's F-12 nutrient mixture (in a ratio of 1:1) (Wako Pure Chemical Industries, Osaka, Japan) and $5 \mathrm{~mL}$ of the patient's blood serum. Tissue was collected from the degenerated IVD at the level scheduled for intervertebral fusion surgery.

The NP and annulus fibrosus were carefully separated, and the NP tissue was isolated under a dissecting microscope. The NP tissue was transferred to a $100 \mathrm{~mm}$ diameter culture dish, and appropriate cleaning was performed with saline (Fishizarutsu FC, at Fuso Pharmaceutical Industries, Tokyo, Japan) if there was attached blood. The tissue was placed into a $50 \mathrm{~mL}$ conical tube and weighed. Then, it was transferred back to a $100 \mathrm{~mm}$ diameter culture dish. The tissue was minced uniformly to a size of approximately 3-5 mm using a sterile scalpel. The minced NP tissue was again put into a $50 \mathrm{~mL}$ conical tube using $30 \mathrm{~mL}$ saline, and the conical tube containing the tissue was centrifuged at $400 \times g$ for $5 \mathrm{~min}$. The supernatant was kept for sterility testing on bacillus and mycoplasma.

The NP tissue was treated with enzymes in accordance with existing protocols. A piece of tissue after centrifugation was resuspended with $10 \mathrm{~mL}$ DMEM/F12/10 \% AS and $10 \mathrm{~mL}$ trypsin (TrypLE Express; Gibco, Grand Island, NY) for $1 \mathrm{~h}$ at $37^{\circ} \mathrm{C}$. We performed stirring in a SI-360 shaking incubator (ASONE, Osaka, Japan) with temperature control by warm air and a built-in shaker. After centrifugation at $400 \times g$ for $5 \mathrm{~min}$, the supernatant was removed. The NP tissue was resuspended with $20 \mathrm{~mL}$ Type I collagenase $(0.56 \mathrm{mg} / \mathrm{mL})$ (Worthington Biochemical Corp, Lakewood, NJ, USA) in DMEM/F $12 / 10 \%$ AS for $2 \mathrm{~h}$ at $37^{\circ} \mathrm{C}$. After centrifugation at $400 \times \mathrm{g}$ for $5 \mathrm{~min}$, the mixture of NP cells and tissue debris was suspended with DMEM/F12/10 \% AS $(20 \mathrm{~mL})$ and passed through a cell strainer to isolate the NP cells.

Aspirated bone marrow $(50 \mathrm{~mL})$ was collected from the ilium of the patient during the first fusion surgery. We mixed equal amounts of heparinised aspirated bone marrow and saline with $5 \%$ dextran (Dextran 200,000; Wako Pure Chemical Industries) and stored the mixture at room temperature. After sedimentation of the red blood cells was confirmed, the separated white blood cell layer was collected and centrifuged at $400 \times g$ for $5 \mathrm{~min}$. The supernatant was again stored for sterility testing on bacillus and mycoplasma. The sedimentary white blood cell layer was washed twice with saline, and all of the cells were suspended in DMEM/F12/10 \% AS containing mononuclear cells. The white blood cells were cultivated

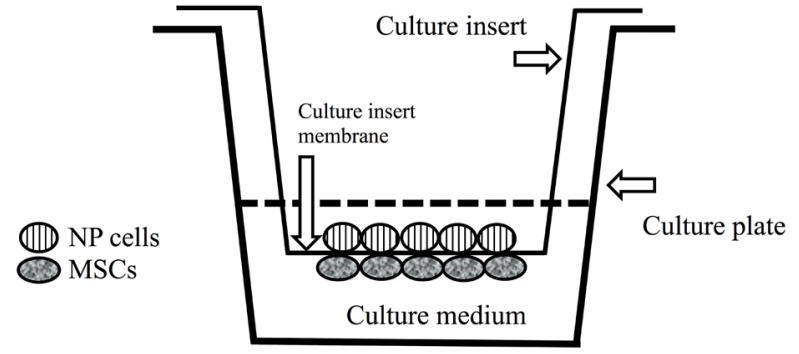

Fig. 1. Co-culture with direct cell-to-cell contact. NP cells in monolayer on the surface of the culture insert membrane were co-cultured with MSCs in monolayer on the reversed side of the culture insert membrane.

in a $100 \mathrm{~mm}$ diameter dish using DMEM/F12/10 \% and pre-cultured for 1-2 h. After pre-culturing, non-adherent bone marrow cells were removed by gentle washing using DMEM/F12/10 \% AS. Adherent cells were considered to contain bone marrow-derived MSCs.

\section{Cell culture method}

A monolayer of NP cells was cultured in a six-well plate (Beckton Dickinson, Franklin Lakes, NJ, USA; $1.0 \times 10^{5}$ cells/mL per well) for $4 \mathrm{~d}$ at $37^{\circ} \mathrm{C}$ in $5 \% \mathrm{CO}_{2}$ inside the incubator. A monolayer of mononuclear cells, which were isolated from the bone marrow and identified as adherent cells, was also cultured in a $100 \mathrm{~mm}$ diameter dish for $4 \mathrm{~d}$ at $37^{\circ} \mathrm{C}$ in $5 \% \mathrm{CO}_{2}$.

After $4 \mathrm{~d}$, the cultured NP cells and MSCs were taken from the culture dish using TripLE Express and washed once with saline. The culture medium was retained for sterility testing on bacillus and mycoplasma.

A six-well culture plate and cell culture inserts (Becton Dickinson) containing a polyethylene terephthalate tracketched membrane with $0.4 \mu \mathrm{m}$ pores at the bottom, were used for the co-culture system. A single-cell suspension of bone marrow-derived MSCs was seeded on the reverse side of the inserts at $3.0 \times 10^{4}$ cells $/ \mathrm{mL}$ per well and precultured for $3 \mathrm{~h}$ to allow the cells to adhere to the surface. The single-cell suspension of NP cells, was seeded on the surface of the inserts at $3.0 \times 10^{4}$ cells $/ \mathrm{mL}$ per well. Both types of cells were co-cultured in direct cell-to-cell contact for $3 \mathrm{~d}$ at $37^{\circ} \mathrm{C}$ in $5 \% \mathrm{CO}_{2}$ incubator. The NP cells were then taken from each well with a cell scraper (Fig. 1).

The NP cells for storage were suspended with $10 \%$ DMSO (NDM-70; Nipro, Osaka, Japan) containing $20 \%$ patient's serum and promptly cryopreserved in a liquid nitrogen container. The NP cells from the remaining culture inserts underwent physical dispersion by a cell scraper for administration to each patient. We adopted a distribution method using a scraper because it was possible to suction cells into the syringe with the needle even after dispersion by a cell scraper, and it was determined that this would not cause problems for administration to the patient. The scraped NP cells were collected and centrifuged at $1800 \mathrm{rpm}$ for $5 \mathrm{~min}$. The supernatant medium was retained for sterility testing for bacillus, virus, mycoplasma, and endotoxin. The NP cells were washed twice with saline. The NP cells for administration to the patient 
were suspended with saline. A small volume of the final suspension was retained for sterility testing for bacillus, virus, and mycoplasma.

The process of cell treatment was recorded in the notes of the transplantation therapy of IVD cells in the cell processing and inspection process for each patient. In addition, the use of cryopreservation to store the NP cells was recorded in the process description. The NP cells were stored and locked in a liquid nitrogen tank within the CPC. The maximum storage period is 10 years after transplantation of the activated NP cells. Documents are also stored for 10 years at the Research Resources Bank at Tokai University Hospital. The dean of the Cell Translation Centre is responsible for storage of the activated NP cells and all associated documentation.

\section{Measurement of cell proliferation and viability}

Cell proliferation was determined by the WST- 8 assay using the Cell Counting Kit-8 (CCK-8; Dojindo Molecular Technology, Gaithersburg, MD, USA). Briefly, NP cells were added to a 96 -well plate. After adding $10 \mu \mathrm{L}$ of prepackaged CCK-8 solution, the plate was incubated for $2 \mathrm{~h}$ at $37^{\circ} \mathrm{C}$ in a humidified atmosphere containing $5 \% \mathrm{CO}_{2}$. The plate was read on a spectrophotometer at $450 \mathrm{~nm}$, and the cell counts were determined using a calibration curve.

\section{Evaluation of virus contamination}

Examination of virus contamination, including Hepatitis B virus (HBV), Human Immunodeficiency virus type 1 (HIV-1), Human T-cell leukemia virus type 1 (HTLV-1), human parvovirus B19NS1 (Parvo.B19NS1), human parvovirus B19VP2 (Parvo.B19VP2), Herpes simplex virus (HSV), varicella zoster virus (VZV), Cytomegalo virus (CMV), Epstein-Barr virus (EBV), human herpes virus type 6 (HHV6), human herpes virus type 7 (HHV7), human herpes virus type 8 (HHV8), hepatitis $\mathrm{C}$ virus (HCV), Human Immunodeficiency virus type 1 -RNA (HIV-1-RNA), and Human T-cell leukemia virus type 1-RNA (HTLV-1-RNA), was performed on the activated NP cells at the end of co-culture by the RT-PCR method.

\section{Evaluation of bacillus contamination}

Aerobic and anaerobic bacillus contamination was evaluated on NP tissue, aspirated bone marrow and patient serum at sample acceptance. NP cells and MSCs at the end of monoculture and activated NP cells at the end of co-culture were also evaluated by the BacT/ALERT ${ }^{\circledR} 3 \mathrm{D}$ Microbial Detection System (bioMérieux, Lyon, France) using BacT/ALERT BPA aerobic culture bottles and BacT/ ALERT BPN anaerobic culture bottles (bioMérieux).

\section{Evaluation of mycoplasma}

Evaluation of mycoplasma using RT-PCR, nested PCR and the culture method was performed on NP tissue, aspirated bone marrow and the patient serum at sample acceptance, on NP cells and MSCs at the end of monoculture, and on activated NP cells at the end of co-culture.

\section{Evaluation of endotoxins}

Evaluation of endotoxins was performed for activated NP cells at the end of co-culture by Toxinometer ET2000
(Wako Pure Chemical Industries) using Limulus ES-2 single test (Wako Pure Chemical Industries).

\section{Procedure of transplantation of activated NP cells}

One million activated autologous NP cells suspended with sterile saline were transplanted into the degenerated disc adjacent to the fusion level $7 \mathrm{~d}$ after the first fusion surgery using a specially designed syringe with a 21 -gauge needle with an inner diameter of $200 \mu \mathrm{m}$. The syringe needle had a dead volume of $98 \mu \mathrm{L}$, so an administration of $1.14 \times 10^{6}$ activated NP cells $/ 800 \mu \mathrm{L}$ sterile saline resulted in an administration of $1.00 \times 10^{6}$ cells $/ 702 \mu \mathrm{L}$ sterile saline. With the patient in the left lateral decubitus position, the procedure was performed through a percutaneous approach under local anaesthesia, controlled with an image intensifier. A summary of the entire process from the collection of NP tissue to transplantation of activated NP cells is provided in Fig. 2.

\section{Clinical follow-up}

Clinical evaluations, laboratory checks and follow-up imaging were performed at 1,2 and 4 weeks, 3 and 6 months, as well as 1,2 and 3 years after transplantation of the activated NP cells. Clinical-outcomes were evaluated using the Japanese Orthopaedic Association (JOA) scoring system for low back pain (Inoue et al., 1986). Peripheral blood tests included counts of white blood cells, neutrophils, red blood cells and platelets, and haematocrit and haemoglobin levels. Blood biochemical tests included analysis of glutamic oxaloacetic transaminase (aspartate transaminase), glutamic pyruvic transaminase (alanine transaminase), lactate dehydrogenase, total and direct bilirubin, total protein, albumin, blood urea nitrogen, serum creatinine, creatine phosphokinase, C-reactive protein, $\mathrm{Na}, \mathrm{K}$ and $\mathrm{Cl}$. Imaging included plain radiographs with dynamic views in standing position, and MRI. In 6 out of 9 patients, we analysed changes in water content semi-quantitatively using MRI by the apparent diffusion coefficient (ADC).

\section{Statistical consideration}

The data are presented as the mean \pm standard deviation. Results were regarded as significant when $p<0.05$. Differences between patients were assessed using ANOVA and post hoc testing at three different time points. With regards to sample size and power, the current study calculated $80 \%$ power to observe at least one patient experiencing an adverse event that occurred with a true frequency of 0.20 with 9 patients (Buöen et al., 2002; Buöen et al., 2003).

\section{Results}

\section{Cell proliferation}

The mass of the NP tissue removed was $7.88 \pm 2.81 \mathrm{~g}$ (range, 3.6-11.9 g). The mean number of NP cells after treatment with enzymes was $1.25 \times 10^{6} \pm 0.84 \times 10^{6}$ (range, $0.71-3.42 \times 10^{6}$ ). Cell viability of each case was in the range of 78.60-92.50\%. After monoculture for $4 \mathrm{~d}$, the mean number of NP cells was $2.35 \times 10^{6} \pm 1.15 \times 10^{6}$ 


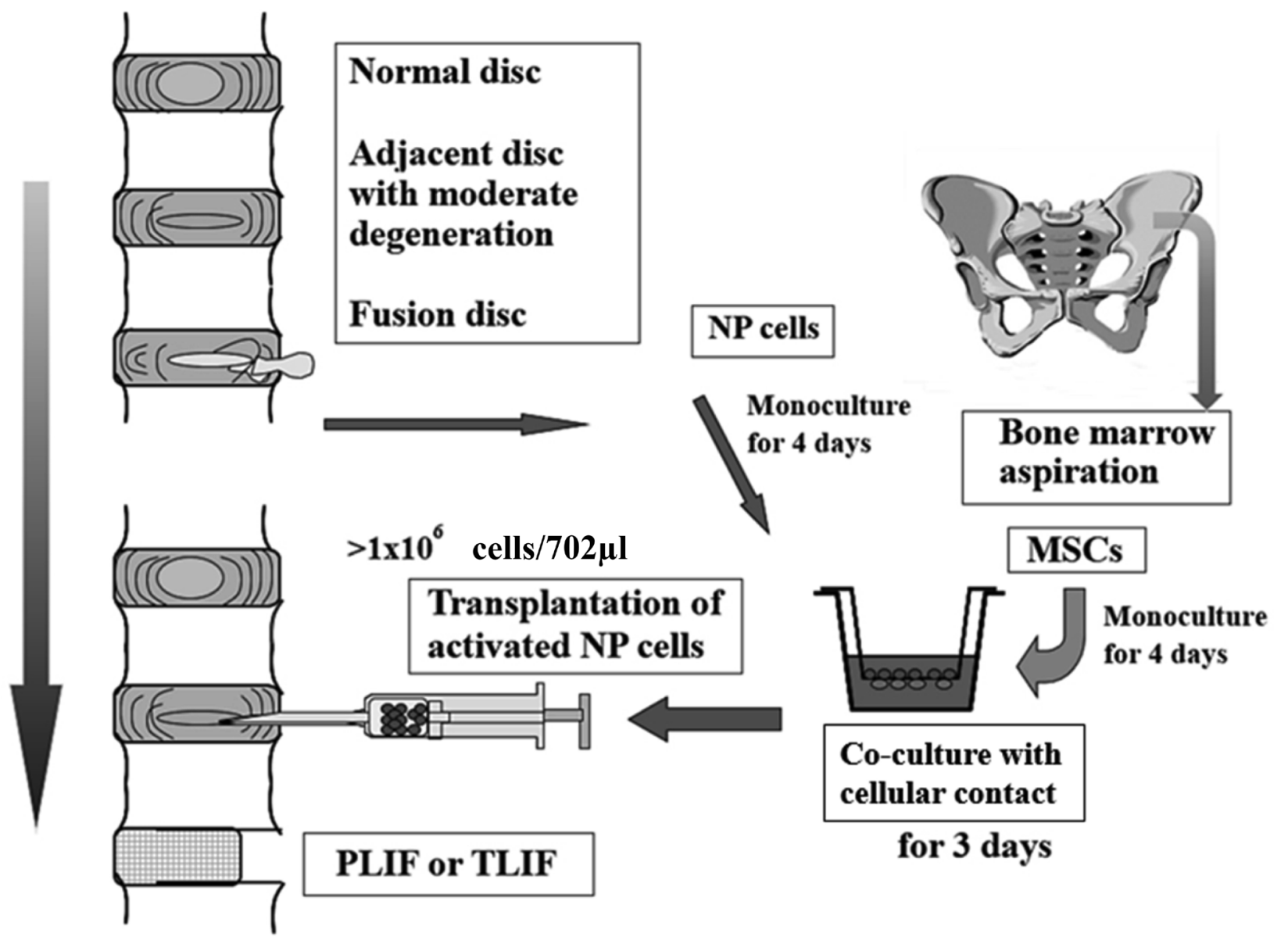

Fig. 2. The entire process from the collection of NP tissue to transplantation of activated NP cells. At the first surgery, tissue was collected from the degenerated IVD at the level scheduled for intervertebral fusion surgery. The NP tissue was treated with enzyme and the NP cells were collected. Aspirated bone marrow was collected from the ilium during the first surgery and the separated white blood cell layer was collected and pre-cultured. Adherent cells were considered to be containing bone marrow-derived MSCs. A monolayer of NP cells and a monolayer of mononuclear cells as the adherent cells were cultured for $4 \mathrm{~d}$. A single-cell suspension of bone marrow-derived MSCs was seeded on the reverse side of the culture inserts and pre-cultured for $3 \mathrm{~h}$. The single-cell suspension of NP cells was seeded on the surface of the culture inserts and both types of cells were co-cultured in direct cell-to-cell contact for $3 \mathrm{~d}$. One million activated autologous NP cells were transplanted into the degenerated disc adjacent to the fusion level $7 \mathrm{~d}$ after the first surgery.

(range, 1.25-4.88 $\times 10^{6}$ ). The mean number of activated NP cells after the co-culture for $3 \mathrm{~d}$ in 9 clinical cases was $5.92 \times 10^{6} \pm 3.72 \times 10^{6}$ (range, $\left.2.98-14.32 \times 10^{6}\right)$. Cell viability was measured with the trypan blue method. The mean proportion of activated NP cells after the co-culture for $3 \mathrm{~d}$ in 9 clinical cases was $95.5 \pm 0.02 \%$ (range, 90.6-98.0\%). In all 9 cases, more than the one million activated NP cells necessary for transplantation could be obtained; the remaining cells were used to conduct safety inspections. The mean number of NP cells at the end of monoculture did not show a significant difference from the mean number of NP cells after treatment with enzyme. However, the mean number of NP cells after co-culture was significantly different from the mean number of NP cells at the end of monoculture, and the mean number of NP cells after co-culture was significantly different from the mean number of NP cells after treatment with enzyme (Fig. 3a, 3b).

\section{Sterility testing}

Testing for the presence of 15 different kinds of viruses in the activated NP cells was carried out at the end of the co-culture, and negative findings were obtained in all cases. The inspection of aerobic and anaerobic bacteria as well as mycoplasma in the NP tissue, aspirated bone marrow, patient serum, NP cells, and MSCs or activated NP cells at each scheduled time point also showed negative findings in all cases. The endotoxin levels in the culture supernatant of the activated NP cells examined $1 \mathrm{~d}$ prior to the end of co-culture and at the end of co-culture were less than $0.002889 \mathrm{EU} / \mathrm{mL}$ and less than $0.002291 \mathrm{EU} / \mathrm{mL}$, respectively, and all levels were normal.

\section{Clinical follow-up}

No clinical adverse events were reported at any follow-up to 3 years after surgery. In the various peripheral blood examinations and biochemical tests, an extremely slight rise 
$\mathrm{x} 10^{6}$

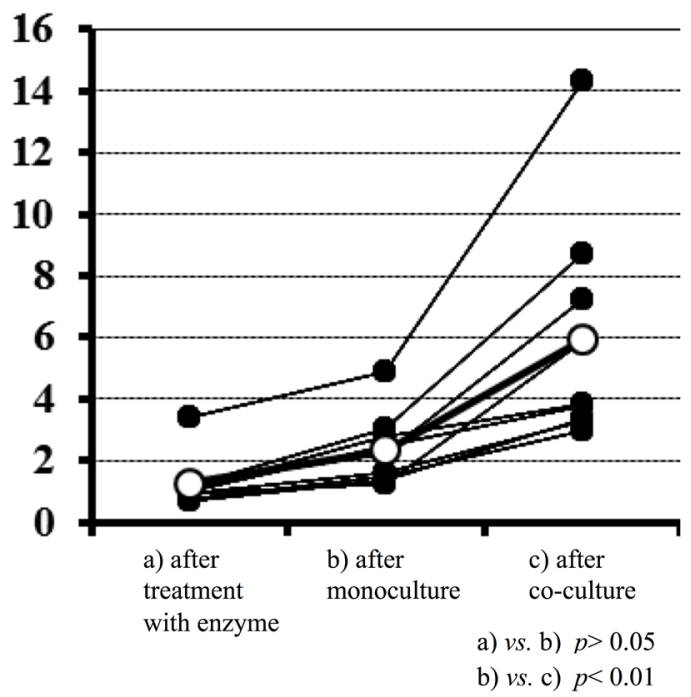

(a)

$$
\times 10^{6}
$$

(b)

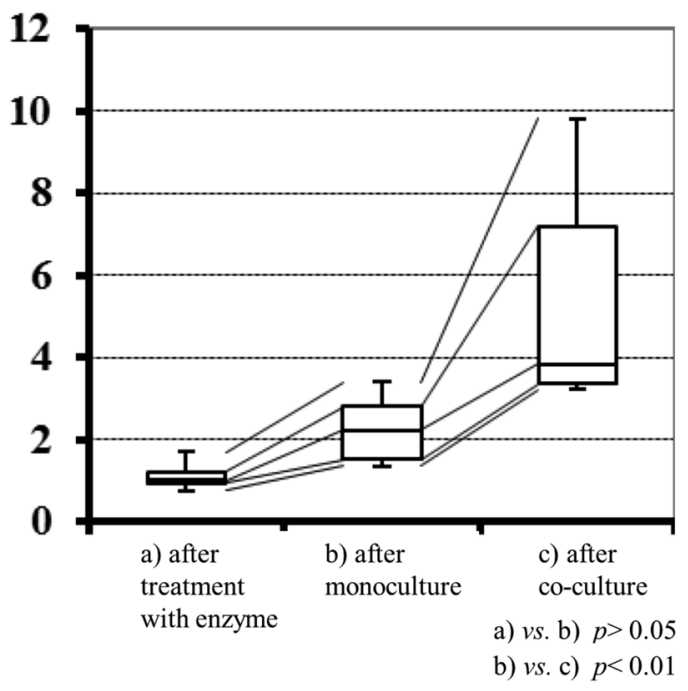

Fig. 3. Cell proliferation. (a) Line chart. The white circles represent the average values from each patient. (b) Box plot. The straight line connecting the data of three time points is a separatrix. It is intended to show the change in clarity of the three data. After treatment with enzyme $v s$. after monoculture, $p>0.05$. After monoculture $v s$. after co-culture, $p<0.01$. After treatment with enzyme $v$. after co-culture, $p<0.01$.

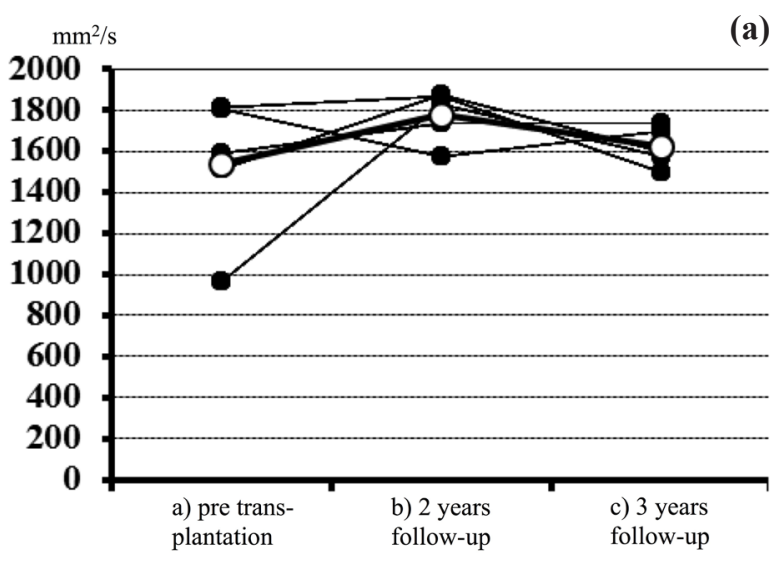

a) vs. b) vs. c) $p>0.05$ $\mathrm{mm}^{2} / \mathrm{s}$

(b)

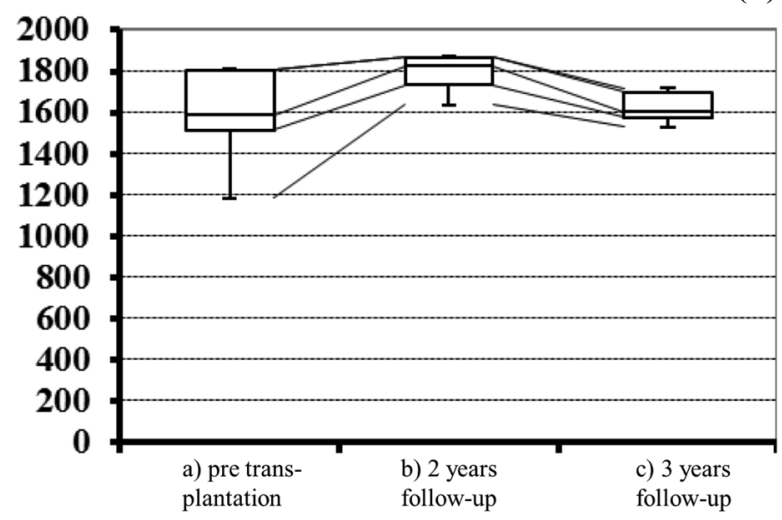

a) $v s$. b) $v s$. c) $p>0.05$

Fig. 4. Evaluation of disc degeneration using apparent diffusion coefficient (ADC). (a) Line chart. The white circles represent the average values from each patient. (b) Box plot. The straight line connecting the data of three time points is a separatrix. It is intended to show the change in clarity of the three data. The mean value of ADC at pretransplantation ( $1 \mathrm{~d}$ prior to cell transplantation), 2 years follow-up, and 3 years follow-up. Pre-transplantation ( $1 \mathrm{~d}$ prior to cell transplantation) $v s .2$ years follow-up, $p>0.05 .2$ years follow-up $v s .3$ years, $p>0.05$. Pre-transplantation (1 d prior to cell transplantation) vs. 3 years follow-up, $p>0.05$.

of the direct bilirubin level was seen after transplantation in 2 of 9 cases at 2 or 4 weeks after transplantation, but the state was normalised immediately afterwards. This has since been determined as a phenomenon entirely irrelevant to transplantation of the activated NP cells. The clinical outcome score using the JOA scoring system improved from $14.2 \pm 4.8$ points preoperatively to $27.2 \pm 1.6$ points at 3 years after transplantation of the activated NP cells (maximum possible score of 29 points). The symptom most likely to occur when degeneration of the adjacent IVD has progressed is an emergence or worsening of low back pain. However, the low back pain subscale score improved from $1.2 \pm 0.5$ points preoperatively to $2.7 \pm 0.2$ points at 3 years after the transplantation (maximum possible score is
3 points for no pain). No deleterious changes in the overall JOA scores were seen.

In terms of social activity before the transplantation, 7 patients were working members of society, and the 2 other patients were university students. All of the patients who worked returned to their original job after an average of 5.8 weeks. One student patient belonged to the physical education department and was able to return to performing the patient's special activity called Kendo, one of the traditional Japanese martial arts. The remaining student went on to work as an agriculturalist after graduation from the university.

The degeneration at the IVD where the activated NP cells were transplanted was less than grade III (according 

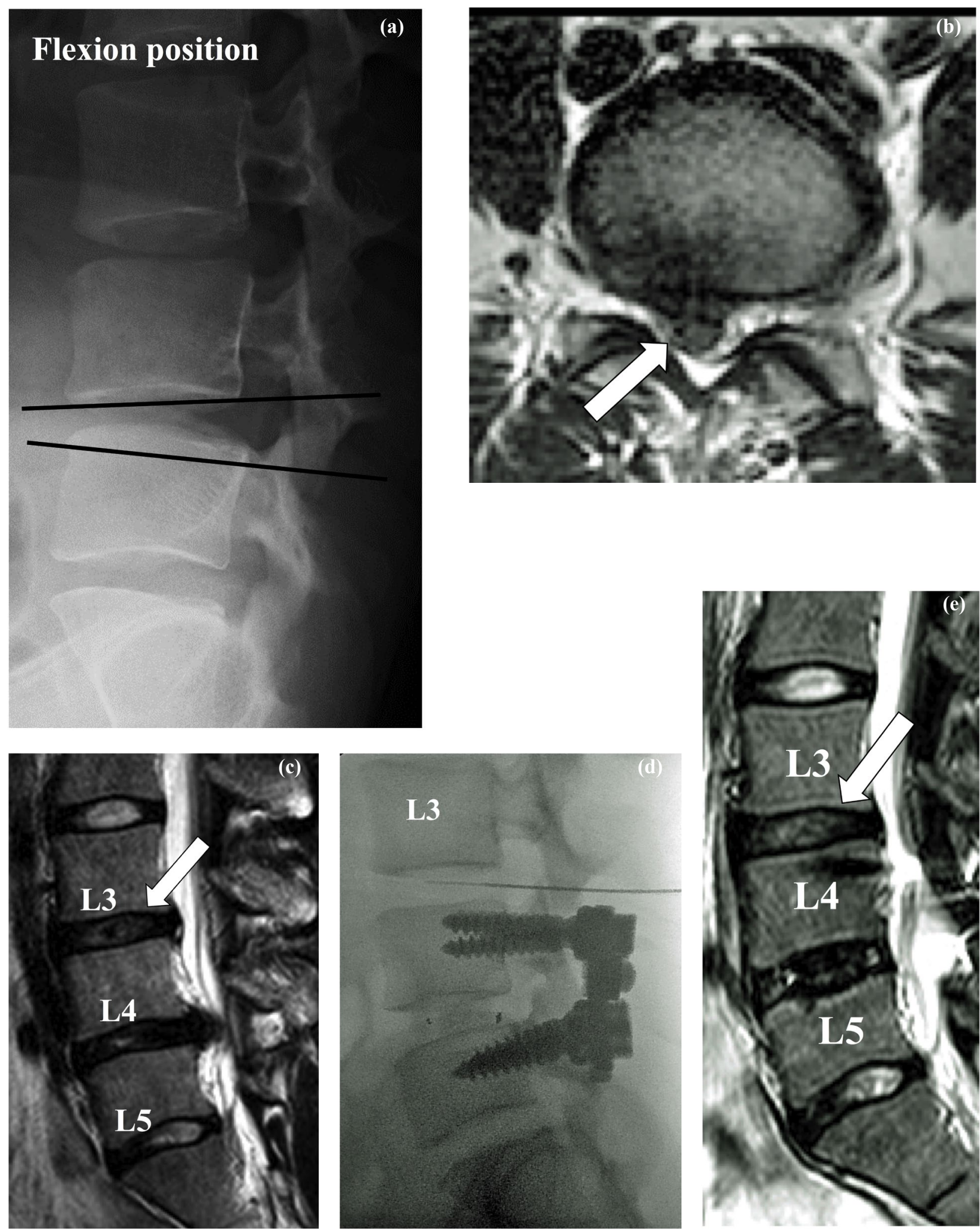

Fig. 5. Images of case 9. (a) Posterior spreading at L4/5 on pre-operative dynamic radiogram. (b) Giant disc herniation at L4/5 (arrow) on the axial view of preoperative MRI T2-weighted image. (c) Pfirrmann's grade III disc degeneration at L3/4 (arrow) adjacent to the intervertebral fusion level on the sagittal view of preoperative MRI T2-weighted image. (d) Transplantation of one million activated NP cells with a specially designed needle set under local anaesthesia. (e) Pfirrmann's grade III disc degeneration at L3/4 (arrow) on the sagittal view of MRI T2-weighted image at 3 years follow-up. 

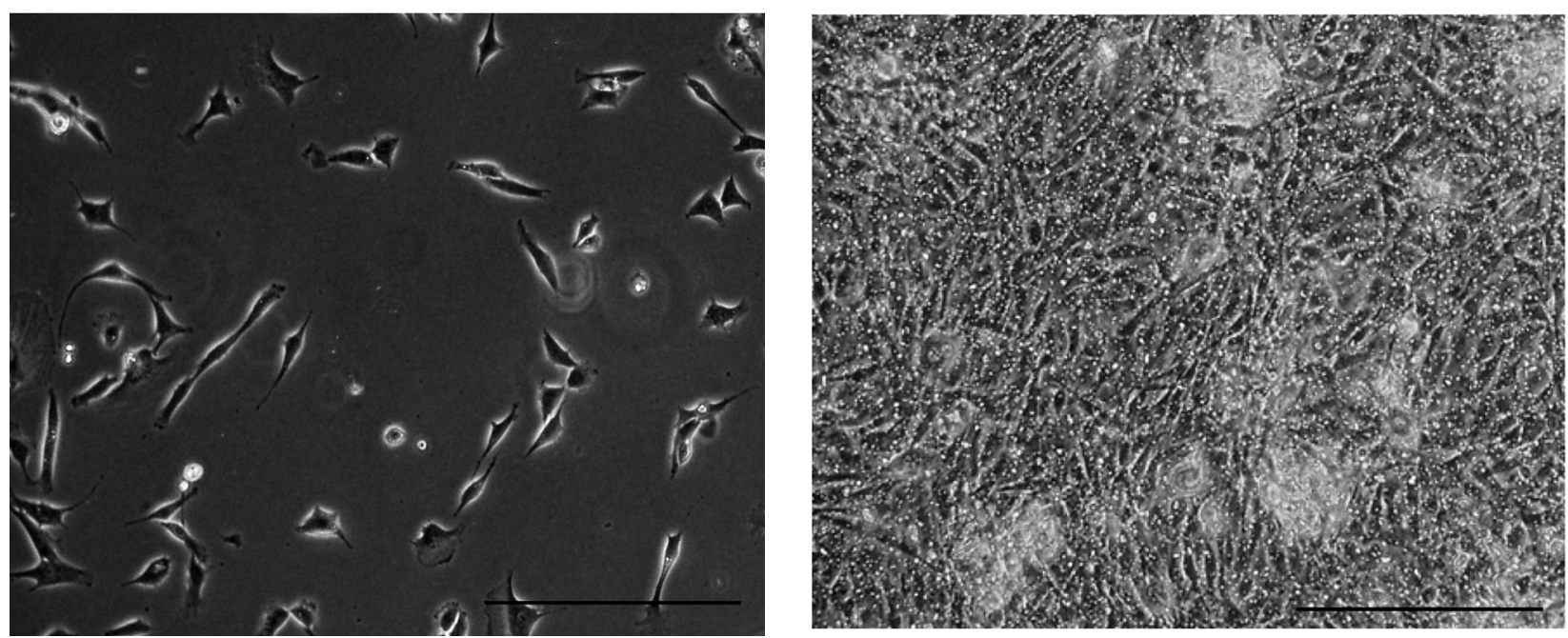

Fig. 6. Activation of NP cells (Case 9). (a) NP cells after $4 \mathrm{~d}$ of monoculture (scale bar is $250 \mu \mathrm{m}$ ). (b) Significantly proliferative NP cells after $3 \mathrm{~d}$ co-culture with the MSCs having direct cell-to-cell contact (scale bar is $250 \mu \mathrm{m}$ ).

to Pfirrmann's classification) on MRI in all cases. There were no examples where degeneration of the transplanted IVD became worse up to the final follow-up at 3 years. Table 2 shows the data at each follow-up, for all cases to 3 years after transplantation of the activated NP cells. No deleterious changes were noted, and a mild improvement on MRI was noted in 1 case.

Diagnosis of the IVD degeneration on MRI using Pfirrmann's classification (Pfirrmann et al., 2001) is a qualitative analysis. Then, we analysed changes in water content semi-quantitatively using MRI by the apparent diffusion coefficient (ADC). In 6 out of 9 cases with transplantation of activated NP cells, the evaluation of disc degeneration was carried out using ADC, and the data at 1 day prior to cell transplantation, and 2 years and 3 years after the transplantation could be obtained in 5 cases. There were no significant differences between the ADC values at the three evaluation points (Fig. 4a, 4b).

There was no posterior spreading of the intervertebral space, spondylolisthesis or narrowing of the intervertebral disc observed in any case.

\section{Case presentation}

A 21-year-old university student suffered from low back pain with sciatica. A radiograph showed posterior spreading at the L4/5 intervertebral space (Fig. 5a), and MRI demonstrated a giant disc herniation with significant disc degeneration (Fig. 5b), indicating spinal fusion at L4/5. The IVD at L3/4 was also detected as having Pfirrmann's grade III degeneration (Fig. 5c). This patient was considered to be a suitable candidate for this clinical study. Fig. 6a shows the NP cells of this patient after $4 \mathrm{~d}$ of monoculture and Fig. $6 \mathrm{~b}$ shows the NP cells after co-culture with the MSCs having cell-to-cell contact. Transplantation of one million activated NP cells was performed under local anaesthesia with a specially designed needle set for transplantation (Fig. 5d). Sagittal MRI at the 3-year follow-up showed an increase in water content and no evidence of detrimental effects according to Pfirrmann's classification (Fig. 5e).

\section{Discussion}

A high-quality disc matrix and maintenance of the number of disc cells are necessary for the restraint of intervertebral disc degeneration. However, the ability of disc cells to reproduce on their own is low. Therefore, it is particularly important to transplant cells to control the degeneration of a moderately degenerated intervertebral disc. We chose cell transplantation among various biologic therapeutics, since cell transplantation with autologous NP cells is more natural physiologically, and autologous transplantation can avoid graft-versus-host reactions. However, our greatest concern is that the capability of NP cells isolated from a degenerated NP alone is not sufficient to slow further disc degeneration. It has been shown that the monoculture of NP cells can enhance the cell numbers, but the number was anticipated as insufficient in terms of quality and quantity of the NP cells for clinical applications (Yamamoto et al., 2003; Watanabe et al., 2010). Kawada et al. (1999) reported that direct cell-to-cell contact enhanced the cell signalling pathways for proliferation in human haematopoietic progenitor cells co-cultured with feeder cells. Yamamoto et al. (2004) adopted this idea of coculture with cell-to-cell contact to show its effect in NP cell activation. Other researchers have also reported on the stimulatory effect of human NP cells with co-culture with MSCs. Yang et al. (2008) showed an increase in cell proliferation, while Le Visage et al. (2006) reported an increase in GAG production in a pellet co-culture system. Furthermore, Vadalà et al. (2008) showed increased NP cell gene expression of collagen II after cell-matrix-cell co-culture with MSCs.

This clinical study was positioned as a phase I clinical trial, and the main purpose was collateral for safety profiling. Determination of sample size in a Phase I trial is not easy. Buöen et al. $(2002,2003)$ have shown that the relationship between detectable event rate and power is not linear, and for small sample sizes, the detectable event rate decreases quickly with increasing sample sizes. For studies 
Table 2. Three years follow-up on MRI and plain radiogram.

\begin{tabular}{|c|c|c|c|c|c|c|c|c|c|c|}
\hline & & Case 1 & 2 & 3 & 4 & 5 & 6 & 7 & 8 & 9 \\
\hline Pre & MRI plain $\mathrm{R}$ & $\begin{array}{c}\text { PF-III, M-mod } \\
(-)\end{array}$ & $\begin{array}{c}\text { PF-III } \\
(-)\end{array}$ & $\begin{array}{c}\text { PF-III } \\
(-)\end{array}$ & $\begin{array}{c}\text { PF-III } \\
(-)\end{array}$ & $\begin{array}{c}\text { PF-III } \\
(-)\end{array}$ & $\begin{array}{c}\text { PF-III } \\
(-)\end{array}$ & $\begin{array}{c}\text { PF-III } \\
(-)\end{array}$ & $\begin{array}{c}\text { PF-III, M-mod } \\
(-)\end{array}$ & $\begin{array}{c}\text { PF-III } \\
(-)\end{array}$ \\
\hline $1 \mathrm{~m}$ & MRI plain $\mathrm{R}$ & $\begin{array}{c}\text { PF-III, M-mod } \\
(-)\end{array}$ & $\begin{array}{c}\text { PF-III } \\
(-)\end{array}$ & $\begin{array}{c}\text { PF-III } \\
(-)\end{array}$ & $\begin{array}{c}\text { PF-III } \\
(-)\end{array}$ & $\begin{array}{c}\text { PF-III } \\
(-)\end{array}$ & $\begin{array}{c}\text { PF-III } \\
(-)\end{array}$ & $\begin{array}{c}\text { PF-III } \\
(-)\end{array}$ & $\begin{array}{c}\text { PF-III, M-mod } \\
(-)\end{array}$ & $\begin{array}{c}\text { PF-III } \\
(-)\end{array}$ \\
\hline $3 \mathrm{~m}$ & MRI plain R & $\begin{array}{c}\text { PF-III, M-mod } \\
(-)\end{array}$ & $\begin{array}{c}\text { PF-III } \\
(-)\end{array}$ & $\begin{array}{c}\text { PF-III } \\
(-)\end{array}$ & $\begin{array}{c}\text { PF-III } \\
(-)\end{array}$ & $\begin{array}{c}\text { PF-III } \\
(-)\end{array}$ & $\begin{array}{c}\text { PF-III } \\
(-)\end{array}$ & $\begin{array}{c}\text { PF-III } \\
(-)\end{array}$ & $\begin{array}{c}\text { PF-III, M-mod } \\
(-)\end{array}$ & $\begin{array}{l}\text { PF-III } \\
(-)\end{array}$ \\
\hline $6 \mathrm{~m}$ & MRI plain $R$ & $\begin{array}{c}\text { PF-III, M-mod } \\
(-)\end{array}$ & $\begin{array}{c}\text { PF-III } \\
(-)\end{array}$ & $\begin{array}{c}\text { PF-III } \\
(-)\end{array}$ & $\begin{array}{c}\text { PF-III } \\
(-)\end{array}$ & $\begin{array}{c}\text { PF-III } \\
(-)\end{array}$ & $\begin{array}{c}\text { PF-III } \\
(-)\end{array}$ & $\begin{array}{c}\text { PF-III } \\
(-)\end{array}$ & $\begin{array}{c}\text { PF-III, M-mod } \\
(-)\end{array}$ & $\begin{array}{c}\text { PF-III } \\
(-)\end{array}$ \\
\hline $1 y$ & MRI plain $\mathbf{R}$ & $\begin{array}{c}\text { PF-III, M-mod } \\
(-)\end{array}$ & $\begin{array}{c}\text { PF-III } \\
(-)\end{array}$ & $\begin{array}{c}\text { PF-III } \\
(-)\end{array}$ & $\begin{array}{c}\text { PF-III } \\
(-)\end{array}$ & $\begin{array}{c}\text { PF-III } \\
(-)\end{array}$ & $\begin{array}{c}\text { PF-III } \\
(-)\end{array}$ & $\begin{array}{c}\text { PF-III } \\
(-)\end{array}$ & $\begin{array}{c}\text { PF-III, M-mod } \\
(-)\end{array}$ & $\begin{array}{l}\text { PF-III } \\
(-)\end{array}$ \\
\hline $2 y$ & MRI plain $\mathbf{R}$ & $\begin{array}{c}\text { PF-III, M-mod } \\
(-)\end{array}$ & $\begin{array}{l}\text { PF-III } \\
(-)\end{array}$ & $\begin{array}{c}\text { PF-III } \\
(-)\end{array}$ & $\begin{array}{c}\text { PF-III } \\
(-)\end{array}$ & $\begin{array}{c}\text { PF-III } \\
(-)\end{array}$ & $\begin{array}{c}\text { PF-III } \\
(-)\end{array}$ & $\begin{array}{c}\text { PF-III } \\
(-)\end{array}$ & $\begin{array}{c}\text { PF-III, M-mod } \\
(-)\end{array}$ & $\begin{array}{c}\text { PF-II III } \\
(-)\end{array}$ \\
\hline $3 y$ & MRI plain $\mathrm{R}$ & $\begin{array}{c}\text { PF-III, M-mod } \\
(-)\end{array}$ & $\begin{array}{c}\text { PF-III } \\
(-)\end{array}$ & $\begin{array}{c}\text { PF-III } \\
(-)\end{array}$ & $\begin{array}{c}\text { PF-III } \\
(-)\end{array}$ & $\begin{array}{c}\text { PF-III } \\
(-)\end{array}$ & $\begin{array}{c}\text { PF-III } \\
(-)\end{array}$ & $\begin{array}{c}\text { PF-III } \\
(-)\end{array}$ & $\begin{array}{c}\text { PF-III, M-mod } \\
(-)\end{array}$ & $\begin{array}{c}\text { PF-II } \sim \text { III } \\
(-)\end{array}$ \\
\hline
\end{tabular}

Plain R: plain radiogram with dynamic view; (-): no additional deleterious changes on plain radiogram such as narrowing of intervertebral height, forward-backward slipping, instability more than $15^{\circ}$ angle, and posterior spreading more than $5^{\circ}$ angle; MRI: MRI T2WI; Pf-III, Pf-II: Pfirrmann's grade III or grade II degeneration on MRI; M-mod: Mochida's moderate degeneration on MRI.

with sample sizes smaller than 6 active subjects, there is much to gain with inclusion of 1 extra subject, but for more than 10 subjects, little is gained by increasing the sample size. With increasing sample sizes, the probability of spontaneous non-treatment-related events also increased, and this background rate needs to be considered when evaluating the trial. They concluded that the active sample sizes in Phase I trials should be between 6 to 10 active subjects. Therefore, we determined that 9 patients are suitable to evaluate the safety of this clinical study. With 9 patients we had $80 \%$ power to observe at least one patient experiencing an adverse event that occurred with a true frequency of 0.20 . No clinical adverse events were reported at any follow-up to 3 years after surgery and our clinical study confirmed the safety of activated NP cell transplantation.

Translating the results obtained in the laboratory into clinical practice is very difficult. Ensuring the safety of the process while working towards its clinical application is the most difficult step, and a number of studies aimed at clinical application are often frustrated at this stage. When applied to clinical cell transplantation, the environment for manipulation of the cells is significantly different from the environment in an ordinary laboratory. In addition to having adequate facilities, such as a CPC or sterilised cabinet machine, a team of skilled technicians is also essential. A committee consisting of experts from various fields is needed to conduct and monitor the study adequately. To provide proper patient selection, to establish a roadmap for cell processing, and to ensure that the facility meets the criteria for cell processing, objective evaluation by a third party is important. Using such a system, the quality of the research leading to clinical applications is protected properly. Our facility was refined to meet all of these requirements at the beginning of enrolment.

During manipulation of the NP cells and MSCs, no abnormal findings were obtained for potential contamination by different kinds of virus, bacillus, mycoplasma or endotoxin; in fact, we could clearly demonstrate that no contamination occurred. The former in vitro study by us, which was described earlier, showed no apparent chromosomal abnormalities or tumourigenic abilities (Watanabe et al., 2010). The evaluation of proteoglycan synthesis and DNA synthesis was not performed in all cases to ensure a sufficient number of transplanted cells. However, our former in vitro clinical study also showed the positive effects of the co-culture system with direct cell-to-cell contact (Watanabe et al., 2010).

In terms of increasing the number of NP cells, better results or results equivalent to those achieved in the laboratory were obtained. No significant difference was observed between the mean number of NP cells after treatment with enzyme and the number after monoculture for $4 \mathrm{~d}$. However, there was a significant difference between the mean number of activated NP cells after co-culture for $3 \mathrm{~d}$ and the number after monoculture for $4 \mathrm{~d}$. The data demonstrated that direct cell-to-cell contact co-culture with MSCs significantly upregulated the viability of NP cells in these clinical cases.

Although this clinical study was aimed primarily at assessing the safety of the procedure, clinical findings to determine minimal efficacy were assessed and followed for 3-years.

The progression of degeneration of the IVD adjacent to the fusion occurred during observation of the cases that underwent one-level intervertebral body fusion and were followed-up, even if the adjacent IVD was normal. Min et al. (2007) reported that adjacent-segment degeneration was found in $82.6 \%$ of the patients of the instrumented posterior lumbar interbody fusion. Harrop et al. (2008) also showed that 314 of 926 (34\%) patients in the lumbar arthrodesis group developed symptomatic adjacent disease, despite opposing reports by Saavedra-Pozo et al., (2014) that the adjacent segment disease is caused by motion segment fusion and the presence of abnormal end-fusion alignment. Therefore, we supposed that progression of degeneration of the IVD adjacent to the fusion certainly 
would occur in more than $30 \%$ of cases in this clinical trial, because all 9 cases showed Pfirrmann's grade III disc degeneration on MRI at the level adjacent to the level scheduled for posterior lumbar intervertebral fusion, which represents moderate degeneration. However, when observed for 3 years after surgery, there was no progression of disc degeneration in 8 of 9 patients at the level with transplantation of activated NP cells, and the remaining 1 case showed an improvement on MRI.

Eighty percent of the tissues of the IVD are composed of water. Therefore, the water content decreases as degeneration progresses. The ADC can show more subtle changes in the water content because it reflects the movement of protons. Therefore, we assumed that ADC was a more reliable method of assessing subtle changes in water content in comparison with $\mathrm{T} 2$ mapping (Wu et al., 2013). No significant differences were noted between the ADC at 1 day prior to cell transplantation, and 2 years and 3 years after the transplantation. This means that no significant increase in disc degeneration at the level adjacent to the level of posterior lumbar intervertebral fusion occurred. Thus, it is possible to conclude that transplantation of the activated NP cells into the moderately degenerated IVD played a minimal role in slowing the further disc degeneration.

On the other hand, disc degeneration is also a natural biological change related to age. As the progression of disc degeneration follows its natural course, mobility of the intervertebral space decreases gradually, and the spine is eventually stabilised. Mild disc degeneration may be part of the natural course, based on the aging of the disc. Performing cell transplantation or adding a liquid component to such a disc with prevention in mind, may results in traumatic acceleration of disc degeneration, altering the natural course of the intervertebral disc.

Because this clinical study was aimed primarily at assessing the safety of activated NP cell transplantation, there are a number of limitations that must be considered before making any conclusive statements regarding longterm safety and efficacy or identifying suitable patients for such treatments. Large-scale clinical trials assessing the mode of transplantation, donor cell numbers, recipient indications, and the therapeutic time window will be needed to define true pathology and patients who will benefit from this procedure. However, based on our results from research conducted over a period of 20 years from basic and translational studies to a novel clinical study, we propose that an effective treatment for moderate IVD degeneration may include cell transplantation, which can be performed safely.

\section{Conclusions}

Our clinical study confirmed the safety of activated NPcell transplantation, and provided promising findings that suggest the minimal efficacy of this treatment to slow the further degeneration of human intervertebral discs.

\section{Acknowledgements}

This work was supported by the Ministry Health, Labour and Welfare (MHLW) in Japan by a Health and Labour Sciences Research Grant (2009-2011). The authors would like to thank K. Ando and H. Kobayashi for their valuable advice, T. Nakai for her help with cell extraction, and Y. Kobayashi, T. Nukaga, M. Tanaka, K. Serigano, T. Iwashina, T. Nomura, M. Okuma and K. Nishimura as co-workers in disc repair during last 20 years. We wish to confirm that there were no known conflicts of interest associated with this publication and there has been no significant financial support for this work that have influenced its outcome.

\section{References}

Alini M, Roughley PJ, Antoniou J, Stoll T, Aebi M (2002) A biological approach to treating disc degeneration: not for today, but may be for tomorrow. Eur Spine J 11(suppl 2): S215-220.

An HS, Thonar EJ, Masuda K (2003) Biological repair of intervertebral disc. Spine 28 (suppl 15): S86-92.

Anderson DG, Tannoury C (2005) Molecular pathogenic factors in symptomatic disc degeneration. Spine J 5(suppl): S260-266.

Buöen C, Holm S, Thomsen MS (2002) Assessment of the cohort size for safety evaluation of one dosing level in first human dose trials. J Clin Pharmacol 42: 1057.

Buöen C, Holm S, Thomsen MS (2003) Evaluation of the cohort size in phase I dose escalation trials based on laboratory data. J Clin Pharmacol 43: 470-476.

Deyo RA, Weinstein JN (2001) Low back pain. N Engl J Med 344: 363-370.

Harrop JS, Youssef JA, Maltenfort M, Vorwald P, Bono CM, Goldfarb N, Vaccaro AR, Hilibrand AS (2008) Lumbar adjacent segment degeneration and disease after arthrodesis and total disc arthroplasty. Spine 33: 17011707.

Hohaus C, Ganey TM, Minkus Y, Meisel HJ (2008) Cell transplantation in lumbar spine disc degeneration disease. Eur Spine J 17 (suppl 4): S492-503.

Inoue S, Kataoka H, Tajima T (1986) Assessment of treatment for low back pain. J Jpn Orthop Assoc 60: 391394.

Iwashina T, Sakai D, Watanabe T, Hiyama A, Omi H, Serigano K, Mochida J (2008) Cell transplantation therapy using activated nucleus pulposus cells for intervertebral disc degeneration. - Present study and future perspective. [In Japanese with English abstract] J Lumbar Spine Disord 14: 63-69.

Kawada H, Ando K, Tsuji T, Shimakura Y, Nakamura Y, Chargui J, Hagiwara M, Itagaki H, Shimizu T, Inokuchi S, Kato S, Hotta T (1999) Rapid ex vivo expansion of human umbilical cord hematopoietic progenitors using a novel coculture system. Exp Hematology 27: 904-915.

Le Visage C, Kim SW, Tateno K, Sieber AN, Kostuik JP, Leong KW (2006) Interaction of human mesenchymal stem cells with disc cells. Spine 31: 2036-2042. 
Min JH, Jang JS, Lee SH (2007) Comparison of anterior- and posterior-approach instrumented lumbar interbody fusion for spondylolisthesis. J Neurosurg Spine 7: 21-26.

Meisel HJ, Siodla V, Ganey T, Minkus Y, Hutton WC, Alasevic OJ (2007) Clinical experience in cell-based therapeutics: Disc chondrocyte transplantation. A treatment for degenerated or damaged intervertebral disc. Biomol Eng 24: 5-21.

Mochida J, Nishimura K, Nomura T, Toh E, Chiba M (1996) The importance of preserving disc structure in surgical approaches to lumbar disc herniation. Spine 21: 1556-1564.

Mochida J, Toh E, Nomura T, Nishimura K (2001) The risks and benefits of percutaneous nucleotomy for lumbar disc herniation. J Bone Joint Surg Br 83: 501-505.

Nishida K, Kang JD, Suh JK, Robbins PD, Evans CH, Gilbertson LCG (1998) Adenovirus-mediated gene transfer to nucleus pulposus cells: implications for the treatment of intervertebral disc degeneration. Spine 23: 2437-2442.

Nishimura K, Mochida J (1998) Percutaneous reinsertion of the nucleus pulposus. Spine 23: 1531-1539.

Okuma M, Mochida J, Nishimura K, Sakabe K, Seiki K (2000) Reinsertion of stimulated nucleus pulposus cells retards intervertebral disc degeneration; an in vitro and in vivo experimental study. J Orthop Res 18: 988-997.

Pfirrmann CWA, Metzdorf A, Zenetti M, Holder J, Boos N (2001) Magnetic resonance classification of lumbar intervertebral disc degeneration. Spine 26: 1873-1876.

Saavedra-Pozo FM, Deusdara RAM, Benzel EC (2014) Adjacent segment disease perspective and review of the literature. Ochsner J 14: 78-83.

Sakai D, Mochida J, Yamamoto Y, Nomura T, Okuma M, Nishimura K, Nakai T, Ando K, Hotta T (2003) Transplantation of mesenchymal stem cells embedded in Atelocollagen gel to the intervertebral disc: A potential therapeutic model for disc degeneration. Biomaterials 24: 3531-3541.

Vadalà G, Studer RK, Sowa G, Spiezia F, Lucu C, Denaro V, Gilbertson LG, Kang JD (2008) Coculture of bone marrow mesenchymal stem cells and nucleus pulposus cells modulate gene expression profile without cell fusion. Spine 33: 870-876.

Yamamoto Y, Mochida J, Sakai D, Nomura T (2003) Reinsertion of nucleus pulposus cells activated by mesenchymal stem cells using coculture method decelerated intervertebral disc degeneration. Spine J 3 (suppl): S101-102.

Yamamoto Y, Mochida J, Sakai D, Nakai T, Nishimura K, Kawada H, Hotta T (2004) Upregulation of the viability of nucleus pulposus cells by bone marrow-derived stromal cell; significance of direct cell-to-cell contact in coculture system. Spine 29: 1508-1514.

Yang SH, Wu CC, Shih TF, Sun YH, Lin FH (2008) In vitro study on interaction between nucleus pulposus cells and mesenchymal stem cells through paracrine stimulation. Spine 33: 1951-1957.

Watanabe T, Sakai D, Yamamoto Y, Iwashina T, Serigano K, Tamura F, Mochida J (2010) Human nucleus pulposus cells significantly enhanced biological properties in a coculture system with direct cell-to-cell contact with autologous mesenchymal stem cells. J Orthop Res 28: 623-630.

Wu N, Liu H, Chen J, Zhao L, Zuo W, Ming Y, Liu S, Liu J, Su X, Gao B, Tang Z, Qiu G, Ma G, Wu Z (2013) Comparison of apparent diffusion coefficient and $\mathrm{T} 2$ relaxation time variation patterns in assessment of age and disc level related intervertebral disc changes. Plos One 8: e69052.

\section{Discussion with Reviewers}

Reviewer II: This clinical study presents a case series of cell therapy to prevent adjacent disc disease above a fused segment. The main finding of the study is the safety of the approach that employs extensive cell expansion in vitro with a co-culture system. The authors elegantly explain all the basic research behind the study necessary for the clinical translation. However, the approach would be easier if the MSCs would be used avoiding the manipulation of two cells population and the co-culture passage. These considerations should be further discussed.

Authors: We believe that use of cells that form the target organ to regenerate is the safest and ideal approach. The procedure to transplant the NP cells that are efficiently activated in vitro is considered to be very safe compared with the use of other cell types and highly compatible with the tissue in the NP cavity. For this reason, this time, we transplanted activated NP cells into the degenerated disc.

Reviewer III: This study is of significant clinical and scientific interest, since it clearly demonstrates the safety and efficacy of autologous activated NP cell transplantation to a moderately degenerative disc. It has been shown in previous studies that cell transplantation correlated with retention of disc height in the transplanted levels. Was the disc height monitored during the observation period of the present study, and could it be maintained?

Authors: Yes, we measured the disc height. Please refer to the parameter Plain $\mathrm{R}$ in Tables $2 \mathrm{a}$ and $2 \mathrm{~b}$. (-) means no additional deleterious changes on plain radiogram such as narrowing of the intervertebral height, forward-backward slipping, instability more than $15^{\circ}$, and posterior spreading more than $5^{\circ}$. The data showed the disc height did not decrease during the 3-year follow-up.

Reviewer III: The study results indicate that progression of degeneration could be halted by the transplanted cells; thus, it is of interest to also monitor the non-treated levels. Were the degeneration grade, changes in fluid content and potentially the disc height also monitored for the disc adjacent to the fusion level that was not subjected to cell transplantation?

Authors: We monitored the untreated disc level. No changes to the degeneration grade, fluid content, and disc height at the level adjacent to the fusion level that was not subjected to cell transplantation were observed. 